\title{
Personalized treatment in the eradication therapy for Helicobacter pylori
}

\author{
SAYAKA JINDA ${ }^{1}$, KANAME NAKATANI ${ }^{1,2,3}$, JUNJI NISHIOKA ${ }^{3}$, KAZUNARI YASUDA ${ }^{1,3}$, \\ YOSHIHIRO SOYA ${ }^{4}$, AMIKO HAYASHI $^{1}$, HIDEO WADA $^{1}$ and TSUTOMU NOBORI $^{1,3}$ \\ ${ }^{1}$ Department of Molecular and Laboratory Medicine, Mie University Graduate School of Medicine; \\ ${ }^{2}$ Division of Personalized Medicine, and ${ }^{3}$ Central Clinical Laboratories, Mie University Hospital, Tsu, Mie; \\ ${ }^{4}$ Biotechnology Frontier Project, Toyobo Company, Osaka, Japan
}

Received July 20, 2010; Accepted September 17, 2010

DOI: $10.3892 / \mathrm{ijmm} .2010 .569$

\begin{abstract}
Helicobacter pylori (HP) is known to be a causative bacterium of gastritis and peptic ulcers. The combination treatment consisting of a proton pump inhibitor (PPI), amoxicillin and clarithromycin (CAM) is widely used in eradication therapy, but the eradication fails in some patients. The main causes are CAM resistance of HP and individual variability in PPI metabolism related to the activity of the cytochrome P450 2C19 (CYP2C19) enzyme. In this study, we examined the usefulness of the prediction of the pharmacotherapeutic efficacy using a newly developed analysis system for HP CAM resistance and CYP2C19 genotypes. After obtaining the informed consent from 45 subjects with HPpositive peptic ulcers, biopsy specimens of the gastric mucosa were obtained by endoscopy. HP DNA extracted from the gastric mucosa was examined by the SELMAPPCR method, the direct sequencing method or the singlenucleotide primer extension (SNuPE) method. HP detection rates by culture and the SELMAP-PCR method were $71 \%$ and $100 \%$, respectively. Among 32 cultured HP, CAM resistance was confirmed in 6 samples by the in vitro drug susceptibility test. CAM-resistant gene mutations were also examined by the SELMAP-PCR method using 32 DNAs from cultured HP and the results were consistent with the drug susceptibility test. Among 22 patients, the eradication rate was $77 \%$. Among 4 patients with CAM resistance determined by both the in vitro drug susceptibility test and the SNuPE method, eradication was successful in one intermediate metabolizer (IM), but not in three extensive metabolizers (EMs). Patients were divided into three groups according to their CYP2C19 phenotype: EMs, IMs and poor metabolizers (PMs). The
\end{abstract}

Correspondence to: Dr Kaname Nakatani, Department of Molecular and Laboratory Medicine, Mie University Graduate School of Medicine, 2-174 Edobashi, Tsu, Mie 514-8507, Japan E-mail: nakatani@clin.medic.mie-u.ac.jp

Key words: Helicobacter pylori, clarithromycin resistance, selfselective multi-amplification primers polymerase chain reaction method, single-nucleotide primer extension method eradication rates for 6 EMs, 12 IMs and 4 PMs were $33.3 \%$, $91.7 \%$ and $100 \%$, respectively. Based on these results, the information on CAM resistance in HP and CYP2C19 phenotypes in carriers could predict the pharmacotherapeutic efficacy and probability of eradication. It can then be possible to vary the dosing or to select another drug by the prediction of the pharmacotherapeutic efficacy.

\section{Introduction}

A variety of factors are involved in the development of gastritis and peptic ulcers, but in 1983, Helicobacter pylori (HP) was shown to be a causative bacteria by Marshall and Warren (1). Thereafter, the eradication of HP was considered more important than the administration of anti-ulcer agents in the treatment of HP-positive peptic ulcers. HP has strong urease activity, which generates ammonia from urea. It appears that an ideal environment for HP is produced by the localized neutralization of strongly acidic regions in the stomach. Therefore, it is necessary to modify this environment by eradicating HP.

Most commonly, a combination therapy with a proton pump inhibitor (PPI), amoxicillin (AMPC) and clarithromycin (CAM) was used for HP eradication in Japan. However, the eradication failure rate with this method was about $30 \%$. Individual variability in CAM-resistant HP and PPI metabolism are important factors in this failure rate (2-7).

The CAM resistance rate of HP has recently been reported to be about $30 \%$ and it tends to increase every year. CAM resistance has been found to result from a single-nucleotide substitution on the 23S rRNA gene of HP $(2142 \mathrm{~A}>\mathrm{G}$ or $\mathrm{C}$, $2143 \mathrm{~A}>\mathrm{G}$ ) and CAM resistance can be predicted by detection of this nucleotide substitution. CAM resistance has been analyzed by the CAM susceptibility test using cultured HP and by the PCR-RFLP method or the invader method using HP DNA, but these methods pose problems related to rapidity, operability, economy and universality $(8-14,24)$.

We developed a new single-nucleotide polymorphism detection method combining the SELMAP-PCR (self-selective multi-amplification primers polymerase chain reaction) method and the single-nucleotide primer extension (SNuPE) method using allele-specific primers and KOD-plus DNA polymerase. We examined the usefulness of this method in 
comparison with the direct sequencing method and the CAM drug susceptibility test. Cytochrome P450 (CYP), an enzyme related to the metabolism of many drugs, has gene polymorphisms that are known to be correlated with CYP activity. It has been found that drug efficacy varies due to differences in enzyme activity dependent on these polymorphisms. CYP2C19 which is related to the metabolism of PPI also has gene polymorphisms that have been reported to be related to enzyme activity. More than 20 alleles are present in CYP2C19 polymorphisms, but because only 3 types have been reported in the Japanese population, we developed a method of analysis for these 3 alleles using the SNuPE method (15-20).

In this study, the clinical usefulness of the HP CAM resistance genetic analysis and of the CYP2C19 gene polymorphism analysis was examined.

\section{Materials and methods}

Study subjects. Subjects were 45 patients who were suspected of having HP-positive peptic ulcers and who gave written informed consent. They were examined at hospitals affiliated with the Mie University Hospital, Doshinkai Toyama Hospital, Nagai Hospital or Saiseikai Matsusaka General Hospital. Part of the gastric mucosa specimens obtained during gastroscopic examination was used for the analyses. This study was approved by the Ethics Committees of the Mie University School of Medicine and of each medical institution (Fig. 1).

SELMAP-PCR method. DNA was extracted from one half of a gastric mucosal specimen using the DNeasy Tissue Kit (Qiagen, Hilden, Germany). DNA was assayed by measuring absorbance and was used for subsequent DNA analysis.

The PCR master mix, primer mix and KOD-plus DNA polymerase used in the SELMAP-PCR were supplied by Toyobo (Osaka, Japan). The SELMAP-PCR method was designed based on the allele-specific PCR. A reaction mixture of $25 \mu 1$ in total consisting of $1 \mu \mathrm{g}$ of HP DNA, each primer at $0.4 \mu \mathrm{M}$ and 0.4 units of KOD-plus DNA polymerase was heated to $94^{\circ} \mathrm{C}$ for $2 \mathrm{~min}$, followed by $94^{\circ} \mathrm{C}$ for $15 \mathrm{sec}, 60^{\circ} \mathrm{C}$ for $30 \mathrm{sec}$ and $68^{\circ} \mathrm{C}$ for $30 \mathrm{sec}$ for 35 cycles. Amplification at $68^{\circ} \mathrm{C}$ for 2 min was then performed and the bands of PCR products were verified by ethidium bromide staining after $3 \%$ agarose gel electrophoresis. Primers were designed so that the $320 \mathrm{bp}$ band was observed with the $2142 \mathrm{~A}$ and 2143A wild-types and the 238 bp band was observed with the $2142 \mathrm{G}$ or $2143 \mathrm{G}$ mutations (Table I) (2-14).

The method detected mutations of the HP 23S rRNA gene using one set of primers for amplification of regions including no. 2142 and no. 2143 , and specific primers for $2142 \mathrm{G}$ and $2143 \mathrm{G}$. The band detected at $320 \mathrm{bp}$ was the wild-type and indicated a CAM-susceptible gene. The band detected at 238 bp carried a mutation at region no. 2142 or no. 2143 and indicated a CAM-resistant gene (2-14).

Single-nucleotide primer extension method. The CAM resistance gene and the CYP2C19 gene polymorphisms were analyzed by the SNuPE method $(15,21)$. First, the region including the polymorphisms was amplified with $1 \mu \mathrm{g}$ of DNA extracted from gastric mucosa and a total of $10 \mu 1$ constituting of $5 \mu 1$ of Multiplex PCR Mix (Qiagen) and each

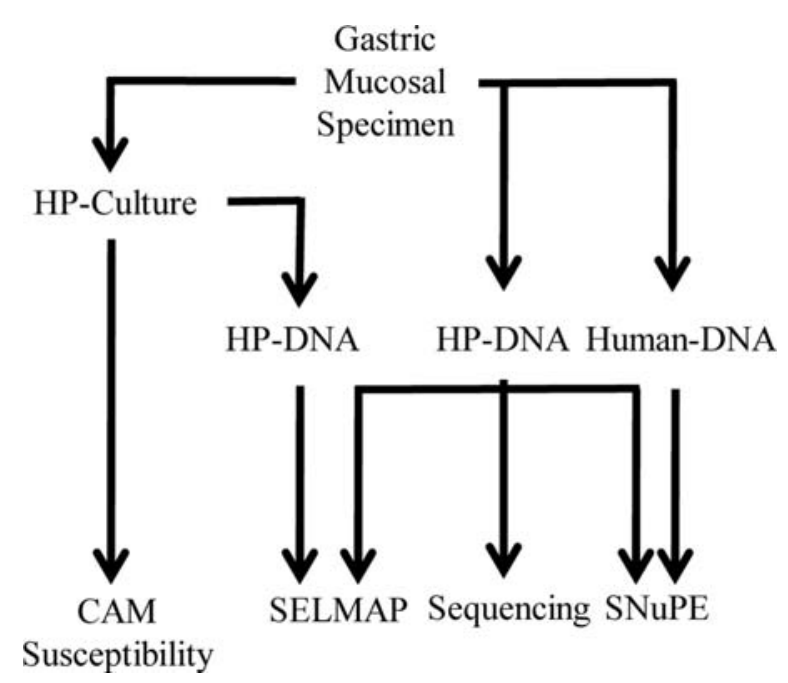

Figure 1. The CAM-resistant gene in HP and the CYP2C19 genotype in humans were analyzed using SELMAP-PCR method and SNuPE method in mucosal specimen. Simultaneously, the HP of the mucosal specimen was cultured and the CAM-susceptibility and the CAM-resistant genes were examined.

primer at $0.2 \mu \mathrm{M}$. The PCR conditions were a reaction at $95^{\circ} \mathrm{C}$ for $15 \mathrm{~min}$ followed by $94^{\circ} \mathrm{C}$ for $30 \mathrm{sec}, 58^{\circ} \mathrm{C}$ for $30 \mathrm{sec}$ and $72^{\circ} \mathrm{C}$ for $30 \mathrm{sec}$ for 35 cycles, followed by an additional extension reaction at $72^{\circ} \mathrm{C}$ for $7 \mathrm{~min}$. The bands of the PCR products were verified by ethidium bromide staining after $2 \%$ agarose gel electrophoresis.

Next, the residual primers and dNTP in the Multiplex PCR products obtained in the above reaction were removed by Calf Intestinal Alkaline Phosphatase (Promega) and Exonuclease I (Takara). PCR for labeling was performed using the SNaPshot ${ }^{\circledR}$ Multiplex Kit (Applied Biosystems) with each primer designed having the $3^{\prime}$ terminal immediately before the SNP region and ddNTP with four-color fluorescent labeling as the template for the PCR products obtained. The PCR products were isolated by the ABI Prism ${ }^{\circledR} 310$ Genetic Analyzer. The software used was the GeneMapper ${ }^{\circledR}$ software v.3.7 (Applied Biosystems) and pattern analysis of the genetic polymorphisms was conducted. The types of added nucleotides were judged based on differences in fluorescent color and mobility. The primers used are shown in Table I.

As only the $* 1, * 2$ and $* 3$ alleles of CYP2C19 have been reported in the Japanese population, a $* 2$ and $* 3$ detection system was constructed. The $* 2$ allele was defined as having a $681 \mathrm{G}>\mathrm{A}$ polymorphism and the $* 3$ allele as having a $636 \mathrm{G}>\mathrm{A}$ polymorphism. It has been reported that CAM resistance arises from a single-nucleotide substitution on the 23S rRNA gene of HP (2142A $>$ G or C, 2143A $>$ G). CAM resistance can be predicted from detection of this nucleotide substitution.

Direct sequence method. Nucleotide sequences were determined by the direct sequence method from amplification products of the CAM resistance gene and CYP2C19 gene polymorphisms obtained by SELMAP-PCR. The BigDye ${ }^{\circledR}$ Terminators v1.1 Cycle Sequencing Kit was used as a template for PCR products obtained by SELMAP-PCR and the products were isolated using the ABI PRISM ${ }^{\circledR} 310$ Genetic Analyzer. The analytical software used was the ABI PRISM DNA sequencing analysis software v.5.2 (Applied Biosystems) and 
Table I. Primers used in the Multi plex PCR and in the SNuPE method.

Primer

\begin{tabular}{|c|c|c|}
\hline \multicolumn{3}{|l|}{ Multi plex PCR } \\
\hline \multirow[t]{2}{*}{ 23S rRNA gene of HP } & Forward & 5'-GAATTGAAGCCCGAGTAAACG-3' \\
\hline & Reverse & 5'-ACCAAGCATTGTCCTGCT-3' \\
\hline \multirow[t]{2}{*}{$2 \mathrm{C} 19 * 2$} & Forward & 5'-AAATTACAACCAGAGCTTGGCA-3' \\
\hline & Reverse & 5'-CACAAATACGCAAGCAGTCACA-3' \\
\hline \multirow[t]{2}{*}{$2 \mathrm{C} 19 * 3$} & Forward & 5'-CTGTGCTCCCTGCAATGTG-3' \\
\hline & Reverse & 5'-TTCACCCCATGGCTGTCTAG-3' \\
\hline \multicolumn{3}{|l|}{ SNuPE method } \\
\hline \multirow[t]{2}{*}{ 23S rRNA gene of HP } & Forward & 5'-TTTTTTTTTTTCCTACCCGCGGCAAGACGG-3' \\
\hline & Reverse & 5'-TTTTTTTTTTGTTGTAAAGGTCCACGGGGTCT-3' \\
\hline $2 \mathrm{C} 19 * 2$ & & 5'-TTCCCACTATCATTGATTATTTCCC-3' \\
\hline $2 \mathrm{C} 19 * 3$ & & 5'-AGGATTGTAAGCACCCCCTG-3' \\
\hline
\end{tabular}

the pattern analysis of the genetic polymorphisms was conducted. The types of added nucleotides were judged based on differences in fluorescent color and mobility.

In vitro drug susceptibility test. After half of each gastric mucosal specimen was cultured on sheep blood agar medium, drug susceptibility tests were performed by Mitsubishi Chemical Medience Co. (Tokyo, Japan). Drug susceptibility tests were performed using the micro-broth dilution method of the Clinical and Laboratory Standards Institute (CLSI), formerly the NCCLA (National Committee for Clinical Laboratory Standards), with CAM resistance defined as a minimum inhibitory concentration (MIC) of $1 \mu \mathrm{g} / \mathrm{ml}$ or higher (22).

$C$-urea breath test $(U B T)$. In the presence of HP, urea in the stomach is degraded by the enzyme urease to generate ammonia and carbon dioxide $\left(\mathrm{CO}_{2}\right)$. The $\mathrm{CO}_{2}$ formed is rapidly transferred from the blood to the lungs and is excreted in the breath as $\mathrm{CO}_{2}$ gas. In this study, ${ }^{13} \mathrm{C}$-urea was used as a test reagent. In patients infected with HP, urea was decomposed and large amounts of ${ }^{13} \mathrm{CO}_{2}$ were detected in the breath. However, in patients not infected with HP almost no ${ }^{13} \mathrm{CO}_{2}$ appeared in the breath because the urea was not degraded (23).

DNA fragment analysis by SNuPE method. In 1 out of 7 patients, CAM-resistant bacteria that could not be cultured were detected by the SNuPE method. Colony PCR (cPCR) was performed in samples with different results by different methods. To investigate the quantitative determination and sensitivity of CAM resistance, various contents (0-100\%) of CAM-resistant HP were checked by the SNuPE method. Sensitivity was determined as a ratio of the peak levels of the electrogram obtained by the GeneMapper ${ }^{\circledR}$ software. The correlation between the mixing ratio and the area ratio by SNuPE were analyzed by the Student's t-test using SPSS statistics (SPSS Japan Inc.).

\section{Results}

Detection of HP using gastric mucosa. In each case HP DNA was amplified by the SELMAP-PCR and single-nucleotide primer extension method using DNA extracted from gastric mucosa, and HP was detected from all 45 specimens (100\%) by both methods. However, HP was detected in cultures of gastric mucosa of only 32 specimens (71\%) (Fig. 2). These 32 specimens were subjected to drug susceptibility tests and examination of the CAM-resistant gene mutation by the SELMAP-PCR method.

Detection of CAM-resistant HP. Among the 32 specimens in which HP could be cultured, CAM resistance was confirmed in 6 specimens $(18.75 \%)$ by the in vitro drug susceptibility test (Table II). CAM-resistant gene mutations were simultaneously examined by the SELMAP-PCR method using 32 DNAs from cultured HP and CAM-resistant gene mutations were confirmed in the 6 samples that were consistent with the drug susceptibility test. The results of CAM resistance using DNA from gastric mucosa by the SELMAP-PCR method, the SNuPE method and the direct sequencing method in 45 samples mostly $(96 \%)$ matched, except for case nos. 11 and 33. In case no. 33, in which HP could not be cultured, the CAM-resistant gene mutation was detected in the gastric mucosal DNA only by the SNuPE method. The detected resistance gene mutations were all $2143 \mathrm{~A}>\mathrm{G}$. However, it was unclear which was correct, since HP was not cultured from gastric mucosa. In case no. 11, cultured HP was grown on the agar medium and 10 colonies were examined by direct sequencing. Three (30\%) out of 10 colonies showed CAM resistance.

The quantitative determination and sensitivity of CAM resistance determination by the SNuPE method were investigated. Various contents of CAM-resistant HP were examined by single-nucleotide primer extension methods. A significant correlation between the premixtured ratios and the measured ratios was observed $(\mathrm{P}<0.001)$ (Fig. 3). This method could quantitatively detect CAM resistance in over $10 \%$ of CAMresistant HPs. 
Table II. CAM resistant genes and 2C19 genotype in 45 subjects.

\begin{tabular}{|c|c|c|c|c|c|c|c|}
\hline \multirow[b]{2}{*}{ No. } & \multicolumn{3}{|c|}{$\begin{array}{l}\text { CAM-resistant gene of HP-DNA } \\
\text { from gastric mucosal specimen }\end{array}$} & \multirow{2}{*}{$\begin{array}{l}\text { Cultured } \\
\text { HP-DNA } \\
\text { SELMAP }\end{array}$} & \multirow{2}{*}{$\begin{array}{c}\text { CAM } \\
\text { susceptibility } \\
\text { MIC }(\mu \mathrm{g} / \mathrm{ml})\end{array}$} & \multirow[b]{2}{*}{ 2C19 genotype } & \multirow[b]{2}{*}{ Eradication } \\
\hline & SELMAP & SNuPE & Sequencing & & & & \\
\hline 1 & $S$ & S & $S$ & $\mathrm{~S}$ & 0.03 & $* 2 / * 2(\mathrm{PM})$ & + \\
\hline 2 & $\mathrm{~S}$ & S & S & S & $\geq 0.015$ & $* 2 / * 3(\mathrm{PM})$ & + \\
\hline 3 & $\mathrm{~S}$ & $\mathrm{~S}$ & $\mathrm{~S}$ & $\mathrm{~S}$ & 0.03 & $* 1 / * 2$ (IM) & + \\
\hline 4 & $\mathrm{~S}$ & $\mathrm{~S}$ & $\mathrm{~S}$ & $\mathrm{~S}$ & 0.03 & $* 2 / * 2(\mathrm{PM})$ & + \\
\hline 5 & $\mathrm{R}$ & $\mathrm{R}$ & $\mathrm{R}$ & $\mathrm{R}$ & 8 & $* 1 / * 1(\mathrm{EM})$ & - \\
\hline 6 & $\mathrm{~S}$ & $\mathrm{~S}$ & $\mathrm{~S}$ & $\mathrm{~S}$ & 0.06 & $* 1 / * 3$ (IM) & + \\
\hline 7 & $S$ & S & $\mathrm{S}$ & ND & $\mathrm{ND}$ & $* 1 / * 3$ (IM) & ND \\
\hline 8 & $\mathrm{~S}$ & S & S & ND & ND & $* 1 / * 1(\mathrm{EM})$ & + \\
\hline 9 & $\mathrm{~S}$ & S & S & ND & ND & $* 1 / * 2(\mathrm{IM})$ & + \\
\hline 10 & $\mathrm{~S}$ & S & S & S & $\geq 0.015$ & $* 1 / * 2$ (IM) & - \\
\hline 11 & $\mathrm{~S}$ & $\mathrm{~S} / \mathrm{R}$ & $\mathrm{S}$ & $\mathrm{R}$ & 32 & $* 1 / * 1(\mathrm{EM})$ & - \\
\hline 12 & $\mathrm{R}$ & $\mathrm{R}$ & $\mathrm{R}$ & $\mathrm{R}$ & 16 & $* 1 / * 1(\mathrm{EM})$ & ND \\
\hline 13 & $\mathrm{~S}$ & $\mathrm{~S}$ & $\mathrm{~S}$ & $S$ & $\geq 0.015$ & $* 1 / * 2$ (IM) & ND \\
\hline 14 & $\mathrm{R}$ & $\mathrm{R}$ & $\mathrm{R}$ & $\mathrm{R}$ & 16 & $* 1 / * 2$ (IM) & + \\
\hline 15 & $\mathrm{R}$ & $\mathrm{R}$ & $\mathrm{R}$ & $\mathrm{R}$ & 32 & $* 1 / * 1(\mathrm{EM})$ & - \\
\hline 16 & $\mathrm{~S}$ & S & $\mathrm{S}$ & $\mathrm{S}$ & $\geq 0.015$ & $* 1 / * 3(\mathrm{IM})$ & + \\
\hline 17 & $\mathrm{~S}$ & S & S & S & 0.12 & $* 2 / * 2(\mathrm{PM})$ & + \\
\hline 18 & $S$ & S & S & S & $\geq 0.015$ & $* 1 / * 2 \quad(\mathrm{IM})$ & + \\
\hline 19 & $\mathrm{~S}$ & S & S & S & $\geq 0.015$ & $* 1 / * 3(\mathrm{IM})$ & + \\
\hline 20 & $\mathrm{~S}$ & S & S & S & 0.06 & $* 1 / * 2$ (IM) & ND \\
\hline 21 & $\mathrm{~S}$ & S & S & S & $\geq 0.015$ & $* 1 / * 3$ (IM) & + \\
\hline 22 & $\mathrm{~S}$ & S & $S$ & S & 0.03 & $* 1 / * 1(\mathrm{EM})$ & + \\
\hline 23 & $S$ & S & S & S & $\geq 0.015$ & $* 1 / * 3$ (IM) & ND \\
\hline 24 & $\mathrm{~S}$ & S & S & S & $\geq 0.015$ & $* 1 / * 2(\mathrm{IM})$ & ND \\
\hline 25 & $S$ & S & S & $S$ & $\geq 0.015$ & $* 1 / * 2(\mathrm{IM})$ & ND \\
\hline 26 & $\mathrm{~S}$ & S & S & $\mathrm{S}$ & $\geq 0.015$ & $* 1 / * 1(\mathrm{EM})$ & - \\
\hline 27 & $\mathrm{~S}$ & S & S & ND & ND & $* 1 / * 2$ (IM) & ND \\
\hline 28 & $S$ & S & S & ND & ND & $* 1 / * 1(\mathrm{EM})$ & ND \\
\hline 29 & $\mathrm{~S}$ & S & S & ND & ND & $* 1 / * 2(\mathrm{IM})$ & ND \\
\hline 30 & $\mathrm{~S}$ & S & S & S & 0.03 & $* 2 / * 3(\mathrm{PM})$ & ND \\
\hline 31 & $\mathrm{~S}$ & S & S & ND & ND & $* 1 / * 1(\mathrm{EM})$ & ND \\
\hline 32 & $\mathrm{~S}$ & S & $\mathrm{S}$ & ND & ND & $* 1 / * 3(\mathrm{IM})$ & ND \\
\hline 33 & $S$ & $\mathrm{~S} / \mathrm{R}$ & $S$ & ND & ND & $* 1 / * 1(\mathrm{EM})$ & ND \\
\hline 34 & $\mathrm{~S}$ & S & S & S & $\geq 0.015$ & $* 1 / * 3(\mathrm{IM})$ & + \\
\hline 35 & $\mathrm{~S}$ & S & S & ND & ND & $* 1 / * 1(\mathrm{EM})$ & ND \\
\hline 36 & $\mathrm{~S}$ & S & $S$ & S & 0.03 & $* 1 / * 2(\mathrm{IM})$ & ND \\
\hline 37 & $\mathrm{~S}$ & S & $\mathrm{S}$ & S & $\geq 0.015$ & $* 1 / * 2(\mathrm{IM})$ & + \\
\hline 38 & $\mathrm{~S}$ & S & $\mathrm{S}$ & S & 0.03 & $* 1 / * 2(\mathrm{IM})$ & ND \\
\hline 39 & $S$ & S & $S$ & S & 0.25 & $* 1 / * 2(\mathrm{IM})$ & + \\
\hline 40 & $\mathrm{~S}$ & S & $\mathrm{S}$ & ND & ND & $* 1 / * 2(\mathrm{IM})$ & ND \\
\hline 41 & $\mathrm{R}$ & $\mathrm{R}$ & $\mathrm{R}$ & $\mathrm{R}$ & 32 & $* 1 / * 2(\mathrm{IM})$ & ND \\
\hline 42 & $\mathrm{~S}$ & S & $\mathrm{S}$ & S & 0.03 & $* 1 / * 2(\mathrm{IM})$ & ND \\
\hline 43 & $S$ & $S$ & $S$ & $\mathrm{~S}$ & 0.03 & $* 1 / * 3$ (IM) & ND \\
\hline 44 & $\mathrm{~S}$ & S & $S$ & ND & ND & $* 1 / * 2(\mathrm{IM})$ & ND \\
\hline 45 & $\mathrm{~S}$ & S & $\mathrm{S}$ & ND & ND & $* 1 / * 1(\mathrm{EM})$ & ND \\
\hline
\end{tabular}

S, sensitive; R, resistant; ND, no data; EM, extensive metabolizer; IM, intermediate metabolizer; PM, poor metabolizer. 


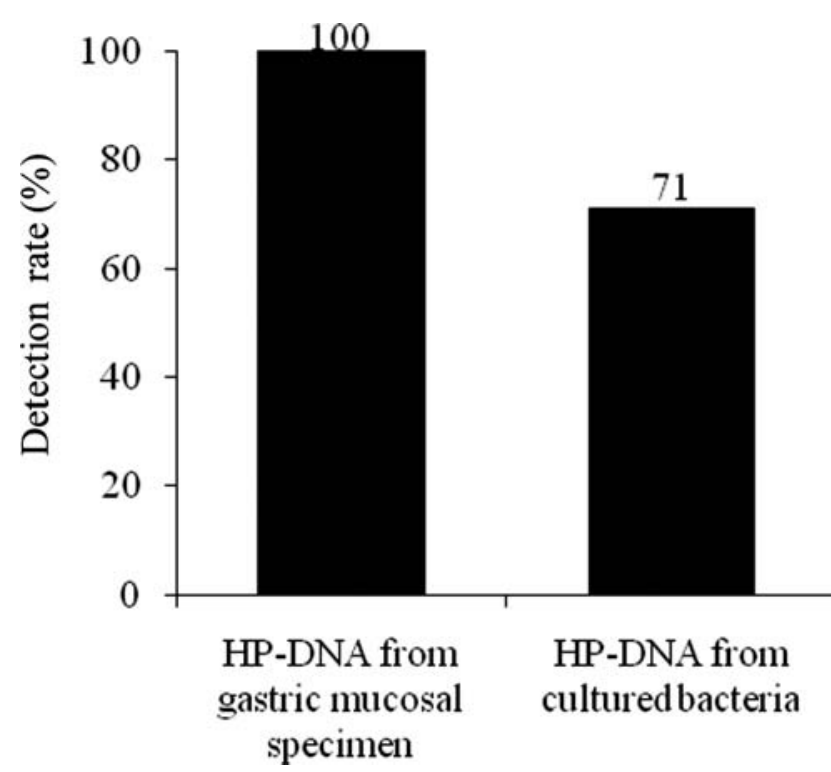

Figure 2. Detection rate of HP-DNA by two different methods. HP-DNA was extracted directly from gastric mucosa or cultured bacteria. Positive detection rates are indicated.

Analysis of CYP2C19 gene polymorphisms (Table II). CYP2C19 gene polymorphisms were analyzed by the SNuPE method using DNA extracted from 45 gastric mucosa specimens. Since only the $* 1, * 2$ and $* 3$ alleles of CYP2C19 have been reported in the Japanese population, $* 2$ and $* 3$ detection was performed. The $* 2$ allele was defined as having a $681 \mathrm{G}>\mathrm{A}$ polymorphism and the $* 3$ allele as having a $636 \mathrm{G}>\mathrm{A}$ polymorphism. The $* 1 / * 1$ phenotype denotes an extensive metabolizer (EM); the $* 1 / * 2$ and $* 1 / * 3$ phenotypes denote an intermediate metabolizer (IM); and the $* 2 / * 3$, $* 2 / * 2$ and $* 3 / * 3$ phenotypes denote a poor metabolizer (PM). Of the patients examined, $12(26.7 \%), 28(62.2 \%)$ and 5 $(11.1 \%)$ were EMs, IMs and PMs, respectively. These gene frequencies were in Hardy-Weinberg equilibrium.

Results of HP eradication (Table II). The HP eradication rates were examined in 22 patients undergoing UBT after eradication therapy. The eradication rate was $77 \%$ (17 patients) and the failure rate was $23 \%$ (5 patients). Among the 5 patients without the eradication, CAM resistance was determined in 3,2, 2 and 3 patients by the in vitro drug susceptibility test, the direct sequencing, the SELMAP-PCR method and the SNuPE method, respectively. In 4 patients in whom CAM resistance were determined by both the in vitro drug susceptibility test and the SNuPE method (cases 5, 11, 14 and 15), eradication was successful in case 14 (an IM), while it failed in the 3 EMs (Fig. 4A).

Among 17 patients with successful eradication, 16 (94\%) patients showed CAM susceptibility as determined by all the methods. In the case of failed eradication (case 14), the CYP2C19 phenotype was IM. In the 6 EMs (cases 5, 8, 11, 15, 22 and 26), the eradication rate was $33.3 \%$ (Fig. 4B). Three of the unsuccessful cases showed CAM resistance and one showed CAM susceptibility. In 12 IMs, the eradication rate was $91.7 \%$ (Fig. 4B). In the unsuccessful case (case 10), no CAM resistance was detected. In the $4 \mathrm{PMs}$, the eradication rate was $100 \%$ (Fig. 4B).

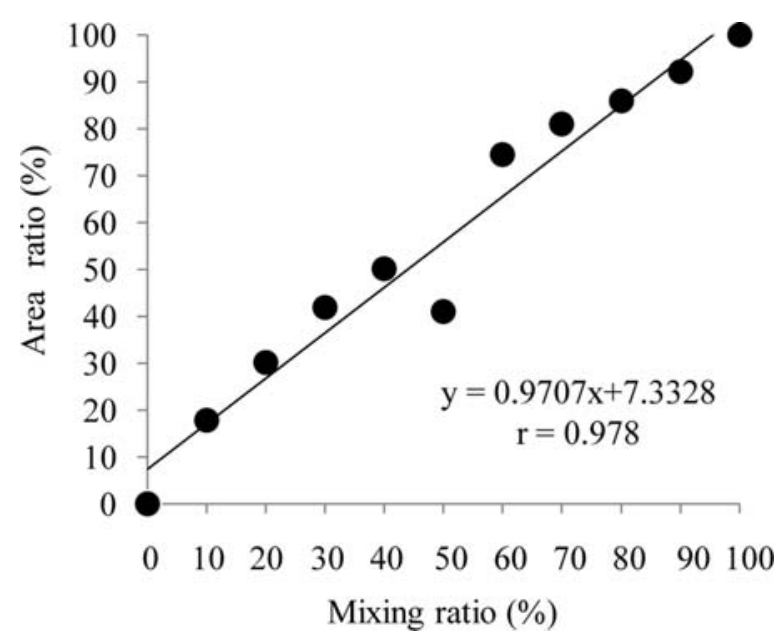

Figure 3. Accuracy and sensitivity of the SNuPE method in detecting CAMresistant HPs. The horizontal axis shows the percentages of mixed CAMresistant HPs. The vertical axis shows the area ratios determined by SNuPE.

\section{Discussion}

To date, CAM resistance has been widely studied using the drug susceptibility test, but there are various problems involved, including the difficulty in culturing HP obtained from the gastric mucosa and the time required. HP DNA was easily amplified from gastric mucosa and was never missed. Tests for CAM-resistant bacteria can be performed simply and rapidly and the results using the SNuPE method, the direct sequencing method or SELMAP-PCR were consistent with those obtained by the drug susceptibility test, which was the gold-standard for determination of drug sensitivity. However, the SELPMAP-PCR method based on the allelespecific PCR shows lower HP-resistant detection sensitivity than the SNuPE method. The SELMAP-PCR method also has its advantages; it is simpler than the SNuPE method and it can be performed using only a gene amplification device. It is thus considered to be a useful test depending on the facility. The major issue is maintaining the current diagnostic accuracy and improving the detection sensitivity in the future.

A method using a DNA chip is also available for analysis of CYP2C19 gene polymorphisms, but it is still too expensive for use in clinical practice. Therefore, we devised an analytical system based on the SNuPE method. This system is not only simple and rapid but also has the same adequate precision as the direct sequencing method. Thus, it is considered to be a powerful tool as a clinical test. The data obtained in this study from 45 patients are consistent with the CYP2C19 phenotype frequencies that we found in 1002 Japanese subjects using DNA chip; frequencies of EM, IM and PM were $32 \%, 50 \%$ and $18 \%$, respectively (data not published). The subjects of this study constituted a population with no genetic bias.

CAM resistance is considered to be a common cause of failure of HP eradication therapy to date. In the present study, it was clear that CAM resistance plays a major role in the eradication rate. Therefore, a rapid CAM resistance gene test should be very useful for predicting the effectiveness of the drug on HP eradication and for the choice between CAM dosing or use of another drug, e.g. metronidazole. 
A

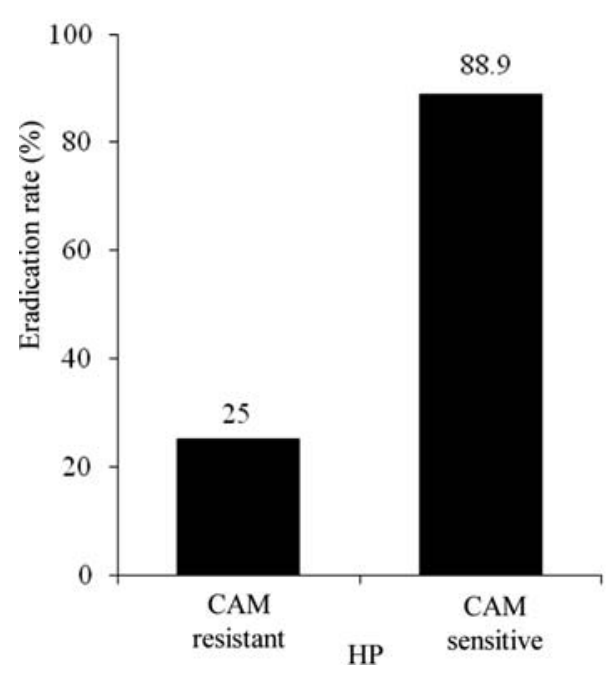

B

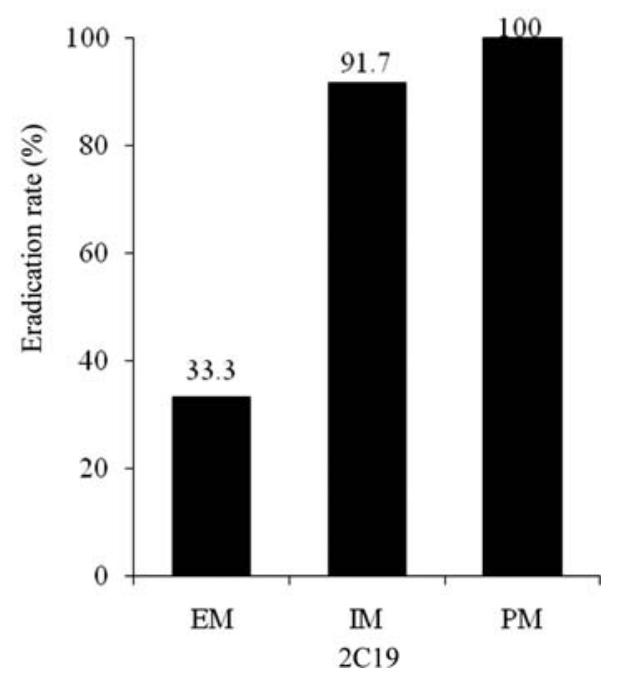

Figure 4. (A) Eradication rate of HP with the CAM-resistant or -sensitive gene. The columns indicate the eradication rates in each group with the CAMresistant or -sensitive gene in HP. (B) Eradication rate of HP according to the CYP2C19 genotype of patients. Patients were divided into three groups based on the metabolic activity of CYP2C19. EM, extensive metabolizer; IM, intermediate metabolizer; PM, poor metabolizer. The columns indicate the eradication rates in each group.

Prediction of the enzyme activity based on CYP2C19 polymorphisms is also involved in the eradication rate. As in previous reports, EMs resulted in a low eradication success rate caused by the lack of an increase in blood PPI levels, which is supported by this study. Therefore, modification of PPI dosing or drugs should be considered based on CYP2C19 genotyping before treatment (2-15).

Taken together, genetic testings of HP and patients before treatment could predict the drug effects in HP eradication therapy. Moreover, combination testing proved to be more useful than performance of a single test. In recent years, the use of companion diagnostic tests have increased, since patients are more likely to benefit from drugs using companion tests. The tests in this study can also contribute to patient benefit not only in the prediction of the drug effects but drug choice before treatment. They will play a critical role in the implementation of personalized healthcare.

\section{Acknowledgments}

The authors thank the endoscopy staff of the Departments of Gastroenterology at Mie University Hospital, Doshinkai Toyama Hospital, Nagai Hospital and Saiseikai Matsusaka General Hospital for their assistance.

\section{References}

1. Warren JR and Marshall BJ: Unidentified curved bacilli on gastric epithelium in active chronic gastritis. Lancet 1: 1273-1275, 1983.

2. Asaka M, Satoh K, Sugano K, et al: Guidelines in the management of Helicobacter pylori infection in Japan. Helicobacter 6: 177-186, 2001.

3. Asaka M, Kato M, Takahashi S, Fukuda Y, Sugiyama T, Ota H, Uemura N, Murakami K, Satoh K and Sugano K: Guidelines for the management of Helicobacter pylori infection in Japan: 2009 revised edition. Helicobacter 15: 1-20, 2010.

4. Hiratsuka M: Development of simplified and rapid detection assay for genetic polymorphisms influencing drug response and its clinical applications. Yakugaku Zasshi 122: 451-463, 2002.
5. Furuta T, Shirai N, Takashima M, Xiao F, Hanai H, Sugimura H, Ohashi K, Ishizaki T and Kaneko E: Effect of genotypic differences in CYP2C19 on cure rates for Helicobacter pylori infection by triple therapy with a proton pump inhibitor, amoxicillin, and clarithromycin. Clin Pharmacol Ther 69: 158$168,2001$.

6. Bytzer P and O'Morain C: Treatment of Helicobacter pylori. Helicobacter 10: 40-46, 2005.

7. Furuta T, Shirai N, Kodaira M, Sugimoto M, Nogaki A, Kuriyama S, Iwaizumi M,Yamade M, Terakawa I, Ohashi K, Ishizaki T and Hishida A: Pharmacogenomics-based tailored versus standard therapeutic regimen for eradication of $H$. pylori. Clin Pharmacol Ther 81: 521-528, 2007.

8. Stone GG, Shortridge D, Versalovic J, Beyer J, Flamm RK, Graham DY, Ghoneim AT and Tanaka SK: A PCR-oligonucleotide ligation assay to determine the prevalence of $23 \mathrm{~S}$ rRNA gene mutations in clarithromycin-resistant Helicobacter pylori. Antimicrob Agents Chemother 41: 712-714, 1997.

9. Taylor DE, Ge Z, Purych D, Lo T and Hiratsuka K: Cloning and sequence analysis of two copies of a $23 \mathrm{~S}$ rRNA gene from Helicobacter pylori and association of clarithromycin resistance with $23 \mathrm{~S}$ rRNA mutations. Antimicrob Agents Chemother 41: 2621-2628, 1997.

10. Debets-Ossenkopp YJ, Brinkman AB, Kuipers EJ, Van den Broucke-Grauls CM and Kusters JG: Explaining the bias in the 23S rRNA gene mutations associated with clarithromycin resistance in clinical isolates of Helicobacter pylori. Antimicrob Agents Chemother 42: 2749-2751, 1998.

11. Oleastro M, Ménard A, Santos A, Lamouliatte H, Monteiro L, Barthélémy P and Mégraud F: Real-time PCR assay for rapid and accurate detection of point mutations conferring resistance to clarithromycin in Helicobacter pylori. J Clin Microbiol 41: 397-402, 2003.

12. Perez Aldana L, Kato M, Nakagawa S, Kawarasaki M, Nagasako T, Mizushima T, Oda H, Kodaira J, Shimizu Y, Komatsu Y, Zheng R, Takeda H, Sugiyama T and Asaka M: The relationship between consumption of antimicrobial agents and the prevalence of primary Helicobacter pylori resistance. Helicobacter 7: 306-309, 2002.

13. Rimbara E, Noguchi N, Kijima H, Yamaguchi T, Kawai $T$ and Sasatsu M: Mutations in the 23S rRNA gene of clarithromycinresistant Helicobacter pylori from Japan. Int $\mathbf{J}$ Antimicrob Agents 30: 250-254, 2007.

14. Chen S, Li Y, Yu C: Oligonucleotide microarray: a new rapid method for screening the 23S rRNA gene of Helicobacter pylori for single nucleotide polymorphisms associated with clarithromycin resistance. J Gastroenterol Hepatol 23: 126-131, 2008. 
15. Nikolausz M, Chatzinotas A, Táncsics A, Imfeld G and Kästner M: The single-nucleotide primer extension ( $\mathrm{SNuPE}$ ) method for the multiplex detection of various DNA sequences: from detection of point mutations to microbial ecology. Biochem Soc Trans 37: 454-459, 2009.

16. http://www.imm.ki.se/CYPalleles/default.htm

17. Fukushima-Uesaka H, Saito Y, Maekawa K, Ozawa S, Hasegawa R, Kajio H, Kuzuya N, Yasuda K, Kawamoto M, Kamatani N, Suzuki K, Yanagawa T, Tohkin M and Sawada J: Genetic variations and haplotypes of CYP2C19 in a Japanese population. Drug Metab Pharmacokinet 4: 300-307, 2005.

18. Furuta T, Ohashi K, Kamata T, Takashima M, Kosuge K, Kawasaki T, Hanai H, Kubota T, Ishizaki $\mathrm{T}$ and Kaneko E: Effect of genetic differences in omeprazole metabolism on cure rates for Helicobacter pylori infection and peptic ulcer. Ann Intern Med 129: 1027-1030, 1998.

19. Kang JM, Kim N, Lee DH, Park YS, Kim JS, Chang IJ, Song IS and Jung HC: Effect of the CYP2C19 polymorphism on the eradication rate of Helicobacter pylori infection by 7-day triple therapy with regular proton pump inhibitor dosage. J Gastroenterol Hepatol 23: 1287-1291, 2008.
20. Zhao F and Wang J: Effect of CYP2C19 genetic polymorphisms on the efficacy of proton pump inhibitor-based triple therapy for Helicobacter pylori eradication: a meta-analysis. Helicobacter 13: 532-541, 2008.

21. Vallone P, Just R, Coble M, Butler J and Parsons T: A multiplex allele-specific primer extension assay for forensically informative SNPs distributed throughout the mitochondrial genome. Int $\mathrm{J}$ Legal Med 118: 147-157, 2004.

22. Clinical and Laboratory Standards Institute: Performance Standards for Antimicrobial Susceptibility Testing 26: 142, 2006.

23. Ohara S, Kato M, Asaka M and Toyota T: Studies of 13C-urea breath test for diagnosis of Helicobacter pylori infection in Japan. J Gastroenterol 33: 6-13, 1998.

24. Nakamura A, Furuta T, Shirai N, Sugimoto M, Kajimura M, Soya $\mathrm{Y}$ and Hishida A: Determination of mutations of the $23 \mathrm{~S}$ rRNA gene of Helicobacter pylori by allele specific primerpolymerase chain reaction method. J Gastroenterol Hepatol 22: 1057-1063, 2007. 